\title{
Helicobacter pylori and upper gastrointestinal disease: a survey of gastroenterologists in the United Kingdom
}

\author{
R Milne, R P H Logan, D Harwood, J J Misiewicz, D Forman
}

\begin{abstract}
The objective of this study was to conduct a survey of the opinions and practices of gastroenterologists in the United Kingdom concerning the impact of Helicobacter pylori infection on the management of upper gastrointestinal diseases. A postal questionnaire was sent to all medically qualified members of the British Society of Gastroenterology working in the UK. Replies were received from 670 of 1037 eligible BSG members (65\%). Of these, $73 \%$ thought that $H$ pylori was a cause of duodenal ulcer and $84 \%$ thought that eradication of $H$ pylori decreased ulcer recurrence in comparison with acid suppression. While $80 \%$ used anti-H pylori therapy for a chronic relapsing duodenal ulcer, only $25 \%$ used such therapy for an ulcer at first presentation and $17 \%$ never used anti-H pylori therapy for patients with duodenal ulcer. Although $75 \%$ of respondents did not agree that $H$ pylori was a cause of non-ulcer dyspepsia, 69\% used anti-H pylori therapy to treat a patient with this condition. At the time of the survey, $69 \%$ of those who used anti-H pylori therapy adopted some variant of standard triple therapy. Only $7 \%$ routinely tested for bacterial sensitivity to antibiotics and only $22 \%$ assessed their patients for eradication after treatment. There was a lack of consensus about whether $H$ pylori was a cause of gastric ulcer or gastric cancer with only $47 \%$ and $17 \%$ respectively believing in these associations. In conclusion, at the time of the survey, the use of anti-H pylori therapy had been accepted by a majority of specialist UK gastroenterologists in the management of upper gastrointestinal disease. There was, however, a substantial degree of uncertainty and divergence about which patients should be treated. (Gut 1995; 37: 314-318)
\end{abstract}

Keywords: Helicobacter pylori, gastrointestinal disease, duodenal ulcer, gastric cancer, non-ulcer dyspepsia.

The characterisation of the gastric bacterium Helicobacter pylori in $1983^{1}$ and subsequent evidence to show that infection is a major cause of gastritis and peptic ulcer ${ }^{2-4}$ has brought about profound changes in gastroenterological practice. Eradication of $\mathrm{H}$ pylori has become a practical therapeutic option and an important alternative to acid suppression in the management of patients with peptic ulcer disease. ${ }^{4-6}$ As with many new medical developments, ${ }^{7} H$ pylori eradication therapy has been adopted in a haphazard fashion with enthusiasts and sceptics being respectively more or less convinced about the need to change their practice. This study was designed to gauge the state of specialist opinion and practice concerning the role of $H$ pylori in gastroduodenal diseases within the UK in the first half of 1993.

\section{Methods}

Medically qualified members of the British Society of Gastroenterology (BSG), currently working in the UK, were sent a postal questionnaire in February 1993 (copies available from Dr Milne). Reminders were sent to all non-respondents after four and eight weeks. The questionnaire had five sections. The first asked about the respondents' age, specialty, place of work, and amount of upper gastrointestinal work carried out in the previous year. The second section asked about attitudes to the aetiology and treatment of upper gastrointestinal disease (with a particular emphasis on the role of $H$ pylori and the importance of its eradication), using statements to which respondents were asked to indicate their attitude on a five point scale ranging from 'strongly agree' to 'strongly disagree'. The third section asked respondents directly involved in the clinical management of patients how they would treat six cases (described in brief vignettes, see Appendix). These represented patients with: a duodenal ulcer at first presentation; at first recurrence; and after persistent recurrence; a gastric ulcer; a gastric ulcer associated with nonsteroidal anti-inflammatory drug (NSAID) use; and non-ulcer dyspepsia. The fourth section of the questionnaire asked those respondents who offered $H$ pylori eradication therapy about their method of diagnosis, treatment regimens, and follow up procedures. The final section, only for consultant physicians and surgeons, asked about attitudes to clinical trials and treatment protocols for duodenal ulcer patients.

The data were analysed using SPSS for Windows (version 6.0). Most results are presented as simple frequency distributions. We used the standard deviation of attitude scores as a means of consensus (the higher the standard deviation, the less the consensus). We used $t$ tests to compare the mean value 
TABLE I Responses to 'attitude/belief' questions (percentage of total), ranked by standard deviation (SD) of score. Overall number of respondents $=670$

\begin{tabular}{|c|c|c|c|c|c|c|c|c|}
\hline & & $\underset{(n)}{\text { Missing }}$ & $\begin{array}{l}\text { Strongly } \\
\text { agree }\end{array}$ & Agree & Neutral & Disagree & $\begin{array}{l}\text { Strongly } \\
\text { disagree }\end{array}$ & $S D$ \\
\hline & $H$ pylori causes antral gastritis & 11 & $40 \cdot 7$ & $46 \cdot 1$ & $11 \cdot 4$ & $1 \cdot 4$ & 0.4 & 0.744 \\
\hline 2 & $H$ pylori is a causative agent in gastric cancer & 13 & 2.7 & & & 21.8 & & \\
\hline 3 & $\begin{array}{l}\text { In comparison with } \mathrm{H}_{2} \text { antagonists, anti- } H \text { pylori therapy } \\
\text {. }\end{array}$ & 14 & 37.5 & $46 \cdot 8$ & $13 \cdot 0$ & $2 \cdot 3$ & 0.5 & 0.777 \\
\hline 4 & The risk of pseudomembranous colitis associated with & 13 & 0.5 & $4 \cdot 1$ & $16 \cdot 1$ & $55 \cdot 6$ & 23.7 & 0.778 \\
\hline 5 & $\begin{array}{l}\text { anti- } H \text { pylori therapy is too great to justify its routine use } \\
\text { In comparison with } \mathrm{H}_{2} \text { antagonists, anti- } H \text { pylori therapy }\end{array}$ & 14 & $15 \cdot 1$ & $43 \cdot 0$ & $36 \cdot 4$ & $5 \cdot 2$ & $0 \cdot 3$ & 0.803 \\
\hline 6 & $\begin{array}{l}\text { for } \mathrm{DU} \text { disease will be cheaper in the long run } \\
H \text { pylori is a major factor in the aetiology of gastric ulcer } \\
\text { disease }\end{array}$ & 10 & $7 \cdot 6$ & 38.9 & $40 \cdot 5$ & $12 \cdot 0$ & $1 \cdot 1$ & 0.834 \\
\hline 7 & $\begin{array}{l}\text { In comparison with } \mathrm{H}_{2} \text { antagonists, anti- } H \text { pylori therapy } \\
\text { causes more adverse side effects }\end{array}$ & 16 & $14 \cdot 7$ & $55 \cdot 0$ & $18 \cdot 2$ & 11.6 & 0.5 & 0.870 \\
\hline 8 & $\begin{array}{l}\text { In comparison with } \mathrm{H}_{2} \text { antagonists, anti- } H \text { pylori therapy } \\
\text { decreases patient compliance }\end{array}$ & 15 & $7 \cdot 2$ & $40 \cdot 9$ & $33 \cdot 4$ & $17 \cdot 3$ & $1 \cdot 2$ & 0.890 \\
\hline & $H$ pylori is a major cause of duodenal ulcer disease & 10 & $32 \cdot 0$ & $40 \cdot 9$ & $20 \cdot 0$ & $5 \cdot 8$ & 0.9 & 0.917 \\
\hline 10 & $\begin{array}{l}\text { Lack of compliance with anti- } H \text { pylori therapy is too great } \\
\text { to justify its routine use }\end{array}$ & 13 & 1.2 & 12.5 & $23 \cdot 3$ & $49 \cdot 3$ & 13.7 & 0.913 \\
\hline 11 & $\begin{array}{l}H \text { pylori is a major factor in the aetiology of non-ulcer } \\
\text { dyspepsia }\end{array}$ & 12 & $2 \cdot 4$ & $22 \cdot 6$ & $40 \cdot 0$ & $27 \cdot 5$ & $7 \cdot 4$ & 0.936 \\
\hline 12 & $\begin{array}{l}\text { Anti- } H \text { pylori therapy will become standard treatment for } \\
\text { DU within } 5 \text { years }\end{array}$ & 12 & $14 \cdot 7$ & $39 \cdot 8$ & $32 \cdot 5$ & $10 \cdot 9$ & $2 \cdot 0$ & 0.939 \\
\hline 13 & $\begin{array}{l}\text { The efficacy of anti- } H \text { pylori therapy in DU is still } \\
\text { unproved }\end{array}$ & 13 & $1 \cdot 8$ & $16 \cdot 4$ & $14 \cdot 9$ & $44 \cdot 6$ & $22 \cdot 2$ & $1 \cdot 048$ \\
\hline 14 & $\begin{array}{l}\text { Patients with DU should only be offered anti- } H \text { pylori } \\
\text { therapy in the context of clinical trials }\end{array}$ & 14 & $3 \cdot 7$ & $12 \cdot 8$ & $13 \cdot 4$ & $48 \cdot 0$ & $22 \cdot 1$ & 1.059 \\
\hline 15 & $\begin{array}{l}\text { Patients with NUD should only be offered anti- } H \text { pylori } \\
\text { therapy in the context of clinical trials }\end{array}$ & 14 & $17 \cdot 2$ & $41 \cdot 8$ & 18.9 & $19 \cdot 5$ & $2 \cdot 6$ & 1.069 \\
\hline
\end{tabular}

$\mathrm{DU}=$ duodenal ulcer, $\mathrm{NUD}=$ non-ulcer dyspepsia.

of variables in different groups and the Mann-Whitney $U$ test to compare medians.

\section{Results}

Questionnaires were sent to 1037 eligible members of the BSG and, after two reminders, a total of 670 replies were received, a response rate of $65 \%$. Of the 670 respondents, (637 male, median age 47 years, range 28-68) $412(61 \%)$ were physicians and $155(23 \%)$ were surgeons, while the remaining $103(15 \%)$ were a mixture of pathologists $(8 \%)$, radiologists $(3 \%)$ and other specialists $(4 \%)$. Most respondents were of consultant/senior lecturer grade ( 597 of $670=89 \%$ ) and $344(51 \%)$ worked in district general hospitals, while 293 (44\%) worked in teaching hospitals. Replies were received from all NHS regions in England and from Scotland, Wales, and Northern Ireland.

The amount of upper gastrointestinal clinical work undertaken by the respondents varied widely. The reported median annual number of oesophagogastroduodendoscopies carried out was 300 per respondent (interquartile range 50-500) and a median of 25 (interquartile range $10-50$ ) new patients with duodenal ulcer, 10 (interquartile range 3-25) with gastric ulcer, and 50 (interquartile range 10-150) with non-ulcer dyspepsia were seen each year.

TABLE II Choice of therapy for patients presented in vignettes (see Appendix). Numbers (percentage of respondents)

\begin{tabular}{lllll}
\hline \multicolumn{5}{c}{ Therapy } \\
\cline { 3 - 5 } Patient & Diagnosis & $\begin{array}{l}\mathrm{H}_{2} \\
\text { antagonists }\end{array}$ & $\begin{array}{l}\text { Proton pump } \\
\text { inhibitors }\end{array}$ & $\begin{array}{l}\text { H pylori } \\
\text { eradication therapy }\end{array}$ \\
\hline 1 & Duodenal ulcer (initial presentation) & $423(75)$ & $32(6)$ & $140(25)$ \\
2 & Duodenal ulcer (first recurrence) & $342(61)$ & $48(9)$ & $211(38)$ \\
3 & Duodenal ulcer (relapsing) & $44(8)$ & $99(18)$ & $447(80)$ \\
4 & Gastric ulcer & $300(54)$ & $129(23)$ & $211(38)$ \\
5 & Gastric ulcer (NSAID-associated) & $287(51)$ & $220(39)$ & $99(18)$ \\
6 & Non-ulcer dyspepsia & $90(16)$ & $21(4)$ & $385(69)$ \\
\hline
\end{tabular}

Eighty seven respondents (13\%) reported having had their own $H$ pylori status tested and, of these, $37(43 \%)$ tested positive and 50 $(57 \%)$ were negative. Ten respondents had their infections successfully treated.

Table I shows the responses to the 15 attitudinal questions, presented in order of increasing standard deviation. Five of the questions were concerned with beliefs about the aetiological role of $H$ pylori. There was strong consensus and agreement that $H$ pylori was a cause of antral gastritis ( $87 \%$ agreeing with statement 1 ) and duodenal ulcer (73\% agreeing with statement 9 ). In contrast, only $7 \%$ and $25 \%$ of respondents agreed that it was a cause of gastric cancer (statement 2) and non-ulcer dyspepsia (statement 11) respectively. Many respondents were neutral about the role of $H$ pylori in gastric cancer ( $58 \%$ neutral), gastric ulcer $(41 \%)$, and non-ulcer dyspepsia (40\%) and, for all these diseases, a substantial minority of respondents disagreed that the $H$ pylori had a causative role $(25 \%, 13 \%$, and $35 \%$ respectively).

The 10 remaining attitude questions were concerned with the treatment of $H$ pylori. It was generally accepted that eradication of $H$ pylori decreased recurrence rates of duodenal ulcer (84\% agreeing with statement 3 ) but that, in comparison with acid suppression, the therapy caused more side effects (statement 7 ) and decreased patient compliance (statement 8). The lack of compliance was not thought to be sufficiently great to justify withholding $H$ pylori therapy from routine use (statement 10), nor was there a major concern about the risk of pseudo membranous colitis from antibiotic therapy (statement 4). Although $18 \%$ of respondents thought that the efficacy of anti- $H$ pylori therapy for the treatment of duodenal ulcer was still unproved (statement 13), 55\% thought that such therapy would become standard treatment within five years (statement 12). Fifty nine per cent of 
respondents thought that anti- $H$ pylori therapy should only be offered to patients with non-ulcer dyspepsia as part of a clinical trial (statement 15).

A total of 561 respondents ( $71 \%$ physicians, $25 \%$ surgeons, and $4 \%$ others) answered the questions about treatment of the six patients described in the vignettes and the responses are summarised in Table II. For the first presentation of a duodenal ulcer (patient one), 423 respondents $(75 \%)$ said they would use $\mathrm{H}_{2}$ antagonists, $140(25 \%)$ said they would use anti-H pylori therapy, and $32(6 \%)$ said they would use proton pump inhibitors (the percentages total to more than $100 \%$ as a few respondents suggested more than one treatment).

A similar pattern was seen for patient two, who had a duodenal ulcer at first recurrence. In this case, 342 respondents $(61 \%)$ said they would use $\mathrm{H}_{2}$ antagonists, $211(38 \%$ ) anti$H$ pylori therapy, and $48(9 \%)$ proton pump inhibitors. Patient three, with a chronic relapsing duodenal ulcer elicited a different response. Anti-H pylori therapy was the favoured option for 447 respondents (80\%) with 99 (18\%) opting for proton pump inhibitors and $44(8 \%)$ for $\mathrm{H}_{2}$ antagonists.

On the basis of responses to vignettes one to three, 527 of 561 respondents $(94 \%)$ could be put into one of four categories in terms of their enthusiasm to adopt anti- $H$ pylori therapy for duodenal ulcer disease. There were 117 of $527(21 \%)$ respondents who would use anti- $H$ pylori therapy on patients one, two, and three, 76 (14\%) who would use it for patients two and three, $239(43 \%)$ who would only use it for patient three, and 95 $(17 \%)$ who would not use anti-H pylori therapy on any of the three patients. A direct comparison of the 117 respondents who were enthusiastic about the use of eradication therapy (and used it for all three duodenal ulcer patients) with the 95 sceptics (who would not use it for any duodenal ulcer patient) showed that the former were slightly younger (mean 46.0 years compared with 48.7 years, $p=0.012$ ), had carried out more gastroduodenoscopies (median 400 compared with $200, \mathrm{p}<0.0001$ ), and had seen more new patients with duodenal ulcer in the previous year (median 40 compared with 20 , $\mathrm{p}<0.001)$. A greater proportion of the enthusiasts were physicians $(82 \%$, with $14 \%$ surgeons and $4 \%$ others) compared with the sceptics (44\% physicians, $52 \%$ surgeons, and $4 \%$ others). There was no difference between the two groups in place of work.

Comparing the two groups by their responses to the attitude questions, the sceptics were significantly more likely to believe that $H$ pylori therapy caused more adverse side effects and decreased compliance in comparison with $\mathrm{H}_{2}$ antagonists $(\mathrm{p}<0.001)$. They were also less likely to believe that $H$ pylori was a cause of duodenal ulcer $(p=0.0173)$ and more likely to believe that eradication therapy should be offered to duodenal ulcer patients only in the context of clinical trials $(\mathrm{p}<0.001)$.
A majority of respondents stated that they would treat both of the patients with gastric ulcer (patients four and five) with $\mathrm{H}_{2}$ antagonists, $300(54 \%)$ treating patient four and 287 $(51 \%)$ treating patient six in this way. For the uncomplicated ulcer, anti- $H$ pylor $i$ therapy was the next most popular therapy, mentioned by 211 respondents $(38 \%)$ followed by proton pump inhibitors, mentioned by 129 (23\%). For the NSAID associated ulcer, the use of these latter strategies was reversed with 220 (39\%) favouring proton pump inhibitors and $99(18 \%)$ favouring anti- $H$ pylori therapy.

For patient six, with non-ulcer dyspepsia, 385 respondents $(69 \%)$ said they would use anti- $H$ pylori therapy compared with $90(16 \%)$ using $\mathrm{H}_{2}$ antagonists and 21 (4\%) using proton pump inhibitors.

Of the 519 respondents who treated $H$ pylori, 23 (4\%) were not using a routine test to establish the presence of infection. The majority of the remaining respondents used either histological examination $(74 \%)$ or a biopsy urease test $(58 \%)$ or both, to establish the diagnosis. Other tests used, not necessarily exclusively, were culture $(14 \%)$, urea breath test $(6 \%)$ or serology (3\%). Only $35(7 \%)$ respondents tested for antimicrobial susceptibility.

Three hundred and fifty eight respondents $(69 \%)$ used some form of triple therapy, under which heading were included all regimens that included bismuth, a nitroimidazole, and a second antibiotic, most commonly amoxycillin or tetracycline. There was considerable variation in the triple therapy reported, and although 305 of $358(85 \%)$ followed the Sidney recommendations ${ }^{6}$ as far as drug type is concerned, there was a wide range of doses, frequencies, and treatment durations. The second commonest treatment option was a proton pump inhibitor/antibiotic combination, suggested by $65(13 \%)$ respondents.

Asked if they routinely monitored patients for eradication, 112 of $516(22 \%)$ said they did, although seven did so at less than four weeks, which is the time interval regarded as necessary to elapse for valid assessment of eradication. Sixty six of $112(59 \%)$ used tests requiring further endoscopy, $21(19 \%)$ used serology or the urea breath test, or both, and $14(13 \%)$ used a mixture of both. More of the enthusiasts were likely to test for antimicrobial sensitivity than the sceptics (10\% compared with $6 \%$ ) and more were likely to monitor their patients for bacterial eradication four weeks or more after treatment $(24 \%$ compared with $12 \%$ ), but these differences were not statistically significant.

Of the 501 consultant physicians and surgeons, $394(79 \%)$ stated that large randomised clinical trials were needed to resolve existing uncertainties about the role of $\mathrm{H}$ pylori in duodenal ulcer. In contrast only $55(11 \%)$ were entering patients into such trials although 367 $(73 \%)$ said they would consider joining them. Thirty five per cent of respondents reported having a duodenal ulcer treatment protocol in their department and, of these, 97\% stated it was adhered to often, or nearly always. 


\section{Discussion}

This is the first major survey of UK gastroenterologists on the impact of $H$ pylori infection and associated disease. The response rate of $65 \%$, although similar to that in other surveys of the BSG membership, ${ }^{8}$ is sufficiently low to raise concerns that the respondents might represent a biased sample of members. We believe, however, that our respondents included a high proportion of BSG members directly involved in patient management. It has been estimated that there are 340 consultant gastroenterologists in England and Wales ${ }^{9}$ and we had 274 responses from such a group - that is, a response of $81 \%$. Thus the influence of non-respondents might be of more relevance to the attitude questions than the patient management questions.

By mid-1993, more than one in five gastroenterologists were using $H$ pylori eradication as their first choice therapy in the treatment of a newly diagnosed duodenal ulcer, while four in five treated a persistent relapsing ulcer with such therapy. This represents an important development in clinical practice and indicates that, in a 10 year period, the status of $H$ pylor has progressed from a medical curiosity to a pathogen of enormous clinical significance. It is noteworthy that, at the time of the survey, few large clinical trials or authoritative consensus statements had been published and only one systematic overview of published works on eradication was available. ${ }^{10}$ During the survey period, treatment guidelines, which were derived from recommendations of a Working Party of the Sydney World Congress of Gastroenterology ${ }^{11} 12$ were published. ${ }^{13}$

Despite these rapid therapeutic developments there were approximately $20 \%$ of clinicians who never used eradication therapy in the management of duodenal ulcer disease. Based on their responses to the attitude questions, approximately one third of this group ( $7 \%$ of all gastroenterologists) did not believe that $H$ pylori was a cause of duodenal ulcer. The remaining two thirds (13\% overall) of those not using eradication therapy had concerns about the effectiveness and side effect profile of the treatments then available.

The absence of large clinical trials and a profusion of small, often non-randomised, open studies of $H$ pylori treatment with inconclusive results are additional factors likely to contribute to a reluctance to change prescribing practice and encourage conservatism. ${ }^{14}$ The general confusion about which eradication regimen to adopt was partly shown in the diversity of responses to the open ended question on this subject in the survey. Some of the stated regimens being used were without obvious rationale while others would have resulted in sub-optimal effectiveness (for example, the use of a bismuth drug with a nitroimadozole drug as dual therapy, mentioned by six respondents, or the use of antibiotics in the absence of bismuth or a proton pump inhibitor, mentioned by 22 respondents). Provision of clear advice based on adequately controlled studies may encourage more widespread adoption of eradication therapy.

In 1993 the recommended triple therapy was a complex regimen, involving up to 15 tablets a day for two weeks, with widely variable published eradication success rates and major problems of bacterial resistance to nitroimadozoles and adverse side effects. ${ }^{14}$ Since the survey a number of less complex regimens have been published 61516 some of which have considerably lower drug doses, are highly efficacious, and have less resistance and side effect problems.

Further problems shown by the survey were that, only $7 \%$ of those treating patients with eradication therapy assessed bacterial susceptibility to antibiotics before, while only $22 \%$ routinely checked for successful eradication after, treatment. Facilities for both of these procedures are not routinely available within the NHS and it is possible that lack of availability or prohibitive costs involved, or both, inhibited their uptake.

Despite a degree of conservatism in the use of $H$ pylori eradication therapy for duodenal ulcer disease, a surprising result from this survey was that $69 \%$ of respondents used such therapy for the management of the patient with non-ulcer dyspepsia. This contrasts with the finding that only $25 \%$ believed that $H$ pylori was a cause of non-ulcer dyspepsia. Clinical trials have consistently failed to show an overall benefit of using eradication therapy for this condition. ${ }^{17}$ It is possible that the observed discrepancy between knowledge and behaviour resulted from a lack of any alternative therapeutic options.

As well as providing information about the beliefs and practice among UK gastroenterologists in 1993, we anticipate that the results from this survey could be used to make com-

Appendix - Patient vignettes used

Patient 1 A 26 year old male bank clerk with a 6 month history of intermittent dyspepsia is referred by his GP for endoscopy. $\mathrm{He}$ is a non-smoker and only drinks socially: endoscopy reveals a $4 \mathrm{~mm}$ anterior DU.

Patient 2 A 54 year old non-smoking housewife, with a DU diagnosed by OGD 10 years previously (treated only with 6 months $\mathrm{H}_{2}$ antagonist), was well until 3 months ago when recurrent epigastric pain prompted GP referral: OGD showed duodenitis and multiple duodenal erosions.

Patient 3 A 45 year old labourer with a 25 year history of DU, confirmed by repeated OGD, treated with $\mathrm{H}_{2}$ antagonists and more recently omeprazole, but has never been completely pain free. He smokes 30 cigarettes per day and drinks 4 pints per day. Most recent OGD shows scarring and deformity of the duodenum with a $5 \mathrm{~mm}$ posterior DU.

Patient 4 A 67 year old man with a 4 month history of anorexia and epigastric pain is referred by his GP for urgent OGD which shows a GU $(2 \mathrm{~cm}$ in diameter) at $54 \mathrm{~cm}$ on the lesser curve. Cytology and histology show no evidence of malignancy, but $H$ pylor is present in the biopsies.

Patient 5 A 42 year old non-smoking male accountant with a long history of recurrent dyspepsia/epigastric pain, has been extensively investigated, but all tests (including OGD) are normal. However, antral biopsies show $H$ pylori and an acute on chronic gastritis.

Patient 6 A 78 year old woman recently started on ibuprofen for OA in her hip presents with a 4 day history of increasing lethargy, shortness of breath on exercise, and melena. Hb on admission is $6.4 \mathrm{gm} / 1$. Urgent OGD by the registrar lethargy, shortness of breath on exercise, and melena. Hb on admission is $6.4 \mathrm{gm} / \mathrm{T}$. Urgent OGD by the registrar shows a $3 \mathrm{~cm}$ diameter $\mathrm{GU}$ on the incisura, with no stigmata of recent bleeding. The CLO (Bic
positive. After blood transfusion and stopping ibuprofen, how would you treat this patient? 
parisons with other clinical groups, notably general practitioners, and with gastroenterologists in other countries and, at future time points, in the UK. We hope to be able to monitor changes in attitude and practice both over time and within different sections of the medical profession.

1 Marshall BJ. Unidentified curved bacilli on gastric epithelium in active chronic gastritis. Lancet 1983; i: 1273-5.

2 Dixon MF. Helicobacter pylori and chronic gastritis. In Rathbone BJ, Heatley RV, eds. Helicobacter pylori and gastroduodenal disease. Oxford: Blackwell Scientific, 1992: troduodenal

3 Wyatt JI. Helicobacter pylori, duodenitis and duodenal ulceration. In: Rathbone BJ, Heatley RV, eds. Helicobacter pylori and gastroduodenal disease. Oxford: Blackwel Scientific, 1992: 140-9.

4 National Institutes of Health. Helicobacter pylori in peptic ulcer disease. NIH Consensus Statement 1994: 12: 1-22.

5 Axon A. Drug regimens. In: Northfield TC, Mendall M, Goggin PM, eds. Helicobacter pylori infection. Dordrecht: Kluwer, 1993: 149-57.

6 Tytgat GNJ, Noach LA. H pylori eradication. In: Hunt RH Tytgat GNJ, eds. Helicobacter pylori: basic mechanisms to Tytgat GNJ, eds. Helicobacter pylori: basic mechar
clinical cure. Dordrecht: Kluwer, 1994: 550-69.

7 Rogers EM. Diffusion of innovations. 3rd ed. New York: Free Press, 1993.
8 Boyd EJS, Penston JG, Wormsley KG. Maintenance therapy in duodenal and gastric ulcer disease: survey of
practice amongst British gastroenterologists. Aliment practice amongst British gastroer

9 Neale G, Williams R. Consultant staffing and career prospects in gastroenterology for England and Wales. Gut 1993; 34: 284-7.

10 Chiba N, Rao B, Rademaker JW, Hunt RH. Meta-analysis of the efficacy of antibiotic therapy in eradicating Helicobacter pylori. Am 7 Gastroenterol 1992; 87: 1716-27.

11 Tytgat GNJ, Axon AT, Dixon MF, Graham DY, Lee A, Marshall BJ. Helicobacter pylori: causal agent in peptic ulcer disease? Working Party Reports: World Congress of Gastroenterology, Sydney. Oxford: Blackwell Scientific, 1990: 36-45.

12 Anon. Helicobacter pylori infection - when and how to treat. Drug Ther Bull 1993; 31: 13-5.

13 Axon ATR Duodenal ulcer: the villain unmasked. $B M \mathscr{F}$ 1991; 302: 919-21.

14 Penston JG. Helicobacter pylori eradication - understandable caution but no cause for inertia. Aliment Pharmacol Ther 1994; 8: 369-89.

15 Bazzoli F, Zagari RM, Fossi S, Pozzato P, Alampi G, Simoni $\mathrm{P}$, et al. Short term low dose triple therapy for the eradication of Helicobacter pylori. European fournal of Gastroenterology and Hepatology 1994; 6: 773-7.

16 Logan RPH, Gummett PA, Schaufelberger HD, Greaves RRFH, Mendelson GM, Walker MM, et al. Eradication with clarithromycin and omeprazole. Gut 1994; 35: 323-6.

17 Talley NJ. A critique of therapeutic trials in Helicobacter pylori positive functional dyspepsia. Gastroenterology pylori positive functic 